\title{
Analisis Video Comments to Video Views Ratio Instagram Pada 5 Sepatu Lokal Terbaik Versi Dr. Tirta
}

\author{
Putu Bayu Hardika Raharja Pande \\ bayupande02@gmail.com
}

\begin{abstract}
The era of the Industrial Revolution 4.0 gave a very significant change not only in terms of technology, but also in terms of marketing. Be it service marketing or product marketing. Usually when we market a service or product at least we have to give a little effort. Suppose we have to go to a nearby radio outlet or newspaper print media. Nowadays with the rapid development of technology, we can do marketing from anywhere only through an object that we call a smartphone or smart phone. The purpose of this study is to determine the credibility value of the Instagram account performance of the 5 Best Local Shoe Brands version of Dr. Tirta. There are several steps that must be taken in this research, so as to be able to find the first rank of the Instagram account of the Best Local Shoe Brand version of Dr. Tirta that has the best performance. In this study, Compass Shoes have better performance credibility than other local shoe brands.
\end{abstract}

\begin{abstract}
ABSTRAK
Era Revolusi Industri 4.0 memberikan dampak perubahan yang sangat signifikan bukan hanya dari sisi teknologi saja, tetapi dari sisi pemasaran. Baik itu pemasaran jasa atau pemasaran produk barang. Biasanya kita memasarkan suatu jasa atau produk setidaknya kita harus memberikan sedikit usaha. Misalkan kita harus mendatangi suatu Gerai Radio terdekat atau Media Cetak Koran. Saat ini dengan perkembangan teknologi yang cepat, kita bisa melakukan pemasaran dari mana saja hanya melalui sebuah benda yang kita sebut smartphone atau ponsel pintar. Tujuan dari penelitian ini yaitu mengetahui nilai kredibilitas dari performa Akun Instagram 5 Brand Sepatu Lokal Terbaik versi Dr. Tirta. Ada beberapa langkah yang harus dilakukan dalam penelitian ini, sehingga mampu menemukan peringkat pertama akun Instagram Brand Sepatu Lokal Terbaik versi Dr. Tirta yang memiliki performa terbaik. Pada penelitian ini Sepatu Compass memiliki kredibilitas performa yang lebih baik dibandingkan dengan brand sepatu lokal yang lainnya.
\end{abstract}

Keyword : Social Media Marketing, Social Media Instagram, Video Comments to Video Views Ratio, Brand Sepatu Lokal

\section{PENDAHULUAN}

Era Revolusi Industri 4.0 memberikan dampak perubahan yang sangat signifikan bukan hanya dari sisi teknologi saja, tetapi dari sisi pemasaran. Baik itu pemasaran jasa atau 
pemasaran produk barang. Biasanya kita memasarkan suatu jasa atau produk setidaknya kita harus memberikan sedikit usaha. Misalkan kita harus mendatangi suatu Gerai Radio terdekat atau Media Cetak Koran. Saat ini dengan perkembangan teknologi yang cepat, kita bisa melakukan pemasaran dari mana saja hanya melalui sebuah benda yang kita sebut smartphone atau ponsel pintar.

Tidak dipungkiri dengan hadirnya ponsel pintar banyak memberikan kemudahan dalam kehidupan sehari-hari kita. Selain sisi hardware yang berkembang, dari sisi software atau perangkat lunaknya pun berkembang. Hadirlah apa yang dinamakan dengan sosial media. Suatu wadah yang memberikan kita tempat untuk berbagi apa saja yang bisa kita bagi ke dunia jagat maya. Salah satu yang populer adalah Instagram.

Instagram memberikan kesempatan bagi banyak orang baik pribadi maupun pengusaha untuk memasarkan produknya melalui sosial media ini. Berlomba-lomba menghadirkan sesuatu yang berbeda untuk menarik minat konsumen. Menghadirkan konten-konten yang menghibur dan kreatif. Salah satu industri yang menggunakan jasa sosial media ini adalah industri sepatu lokal.

Salah satu influencer ternama Indonesia yang merupakan seorang dokter dan juga pengusaha menyampaikan pendapatnya mengenai 5 Brand Sepatu Lokal terbaik versinya. Diantaranya ada Ventella Shoes, League Indonesia, Piero Indonesia, Sepatu Compass dan Sagara Indonesia.

\section{TINJAUAN PUSTAKA}

Perkembangan teknologi yang pesat ini sangat mempengaruhi cara kita berkomunikasi dengan konsumen dalam hal memasarkan produk atau usaha kita. Instagram sebagai salah satu sosial media yang terus berkembang dari tahun ke tahun selalu memberikan fitur-fitur baru yang bisa membantu pelaku usaha yang ingin menggunakan jasa promosi menggunakan Instagram.

Tujuan dari Instagram itu sendiri salah satunya yakni sebagai sarana kegemaran dari masing-masing individu yang ingin mempublikasikan kegiatan, barang, tempat ataupun dirinya sendiri ke dalam bentuk foto (Gan Gan Giantika, 2018). Namun perkembangan saat ini di Indonesia, Pengguna Instagram pasti sudah tidak asing dengan promosi barang yang ditawarkan melalui kolom komentar di sebuah post. Tidak jarang ditemui sebuah post foto bukaannya berisi komentar tentang post tersebut, melainkan promosi barang oleh akun lain (Gan Gan Giantika, 2018).

Dengan pesatnya perkembangan teknologi media sosial, telah memberikan dampak terhadap situs-situs komunikasi, dari yang awalnya hanya sekedar email, dan chatting, sekarang sudah banyak jejaringan media sosial yang bisa digunakan sebagai alat komunikasi (I Putu Hendika Pramana, 2021).

Sarana promosi barang terus berubah dari yang menggunakan media cetak seperti koran atau majalan sampai saat ini yang menggunakan sarana media sosial, salah satunya Instagram. Brand local mulai bersaing mempromosikan produknya dengan menampilkan kualitas asli buatan dalam negeri, buatan anak negeri. Disinilah peran media sosial semakin diakui dalam mendongkrak kinerja bisnis. Media sosial memungkinkan bisnis 
kecil dapat mengubah cara berkomunikasi dengan pelanggan, memasarkan produk dan jasa serta saling berinteraksi dengan pelanggan yang bertujuan untuk membangun hubungan yang baik (Eswanti Sugeng Rahayu et al, 2018).

Selain menggunakan media sosial dalam memasarkan produk, terkadang kita juga membutuhkan jasa orang yang dalam hal ini bisa kita katakan terkenal atau biasa disebut influencer atau celebrity endorsement untuk membantu mendongkrak produk yang kita pasarkan. Orang tersebut adalah yang berpengaruh di media sosial, terkenal dan mungkin berkompeten dalam bidang yang sesuai dengan produk yang kita pasarkan. Dengan menggunakan indikator keahlian, kepercayaan dan daya tarik menunjukkan hubungan yang signifikan terhadap niat beli (Dicky Adi Nugroho et al, 2020). Hal ini menunjukkan bahwa celebrity endorsement berpengaruh positif dan signifikan terhadap niat beli (I Putu Gede Handre Haryantana et al, 2015).

\section{METODE PENELITIAN}

Penelitian ini menggunakan metode eksploratif kuantitatif untuk mengetahui kredibilitas dari akun Instagram 5 Brand Sepatu Lokal Terbaik versi Dr. Tirta. Metode eksploratif merupakan penelitian yang memiliki tujuan mengeksplorasi atau memperdalam pengetahuan baru mengenai suatu hal yang baru, juga merumuskan permasalahan secara terperinci (Maryam et al, 2016).

Tujuan dari penelitian ini yaitu mengetahui nilai kredibilitas dari performa Akun Instagram 5 Brand Sepatu Lokal Terbaik versi Dr. Tirta. Ada beberapa langkah yang harus dilakukan dalam penelitian ini, sehingga mampu menemukan peringkat pertama akun Instagram Brand Sepatu Lokal Terbaik versi Dr. Tirta yang memiliki performa terbaik. Langkah-langkah yang dilakukan dalam penelitian ini, diantaranya yaitu :

\section{Melakukan Eksplorasi Pada Website Untuk Menentukan Objek yang Akan} Dianalisa.

Eksplorasi ini dilakukan pada beberapa halaman website yang menyediakan informasi mengenai objek yang akan diteliti. Setelah eksplorasi selesai dilakukan, sehingga ditemukan nama-nama brand sepatu lokal di Indonesia yang akan dijadikan objek analisa. Setelah melakukan eksplorasi pada halaman website, maka langkah selanjutnya yaitu mencari nama akun Instagram dari masing-masing brand sepatu lokal. Pastikan semua brand memiliki akun pada aplikasi sosial media Instagram.

2. Menghitung Nilai Rata-Rata Variabel Dari Top 5 Brand Sepatu Lokal Terbaik versi Dr. Tirta.

Pada langkah ini, peneliti menghitung nilai variable video comments dan variable video views. Variabel merupakan sesuatu yang memiliki nilai bervariasi dimana nilai tersebut dapat dijadikan sebagai dasar untuk empat data yang berbeda seperti rasio, skala, ordinal, nominal dan internal (Rankuti 2015). Untuk menghitung nilai rata-rata dari variabel video comments dan variabel video views yaitu dengan cara mengambil minimal 10 postingan kemudian dihitung sehingga menemukan nilai rata-rata dari masing-masing variabel. 


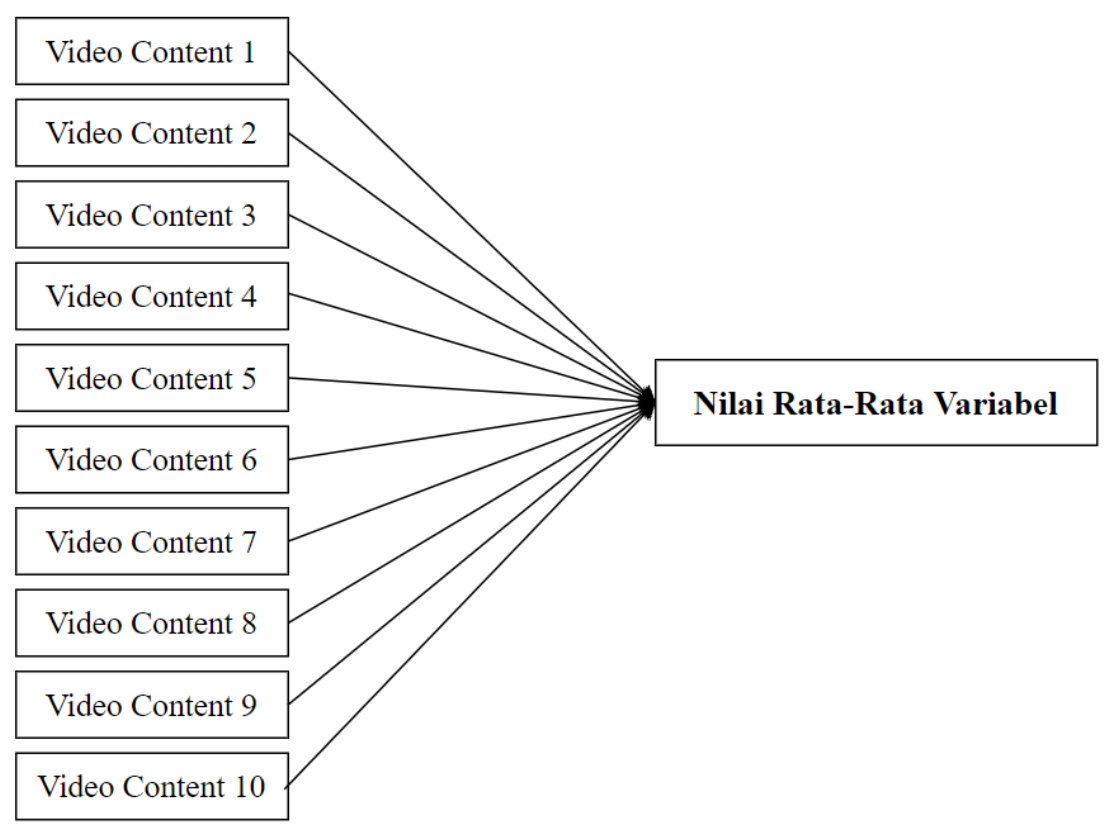

Gambar 1. Analisa Nilai Rata-Rata Variabel.

\section{Menghitung Nilai Kredibilitas Rasio}

Untuk menghitung nilai kredibilitas dari video comments to video views ratio, peneliti menggunakan cara membagi nilai variabel pertama dengan nilai variabel kedua. Jika video comments memiliki nilai 100 dan video views memiliki nilai 300 , maka cara menghitungnya yaitu $100: 300=0,3$. Dengan begitu nilai dari video comments to video views ratio adalah 0,3 .

\section{Menentukan Peringkat Pada Akun Instagram}

Pada langkah terakhir yang dilakukan pada penelitian ini yaitu menentukan peringkat pada masing-masing rasio yang ada. Pada penentuan peringkat perlu melihat karakteristik dari rasio yang diteliti. Jika karakteristik rasio merupakan rendah, maka objek yang memiliki nilai terendah akan mendapatkan angka 5 dan objek yang memiliki nilai tertinggi akan mendapatkan angka 1. Namun jika rasio memiliki karakteristik tinggi maka objek yang mendapatkan nilai tinggi akan mendapatkan angka 5 dan objek yang mendapatkan nilai terendah akan mendapatkan angka 1. Setelah mendapatkan hasil kredibilitas ratio maka dapat disimpulkan objek yang mana mendapatkan peringkat 1 sampai dengan peringkat 5 . 


\section{HASIL DAN PEMBAHASAN}

Akun Instagram dari 5 Sepatu Lokal Terbaik Versi Dr. Tirta, diantaranya :

\section{Ventela Shoes}

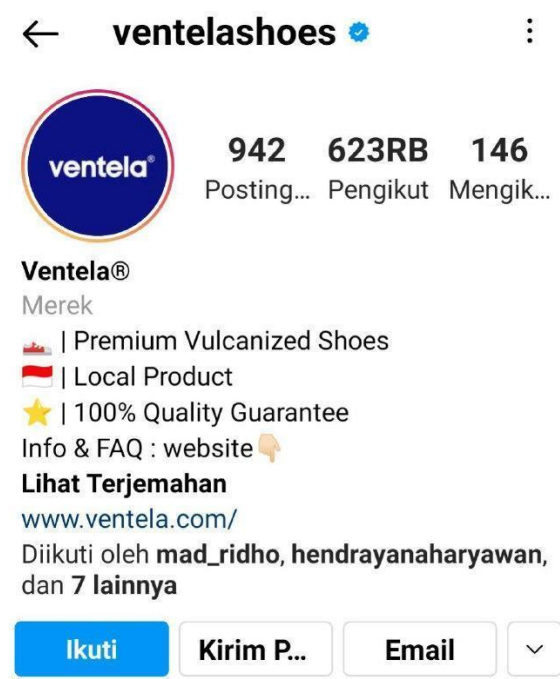

Gambar 1. Akun Instagram Ventela Shoes

Sumber : https://instagram.com/ventelashoes (akses pada 25-10-2021)

\section{League Indonesia}

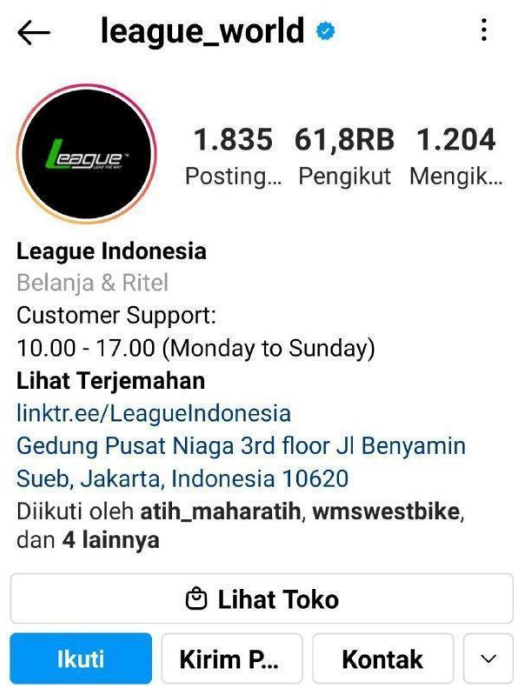

Gambar 2. Akun Instagram League Indonesia

Sumber : https://instagram.com/league_world (akses pada 25-10-2021) 


\section{Piero Indonesia}

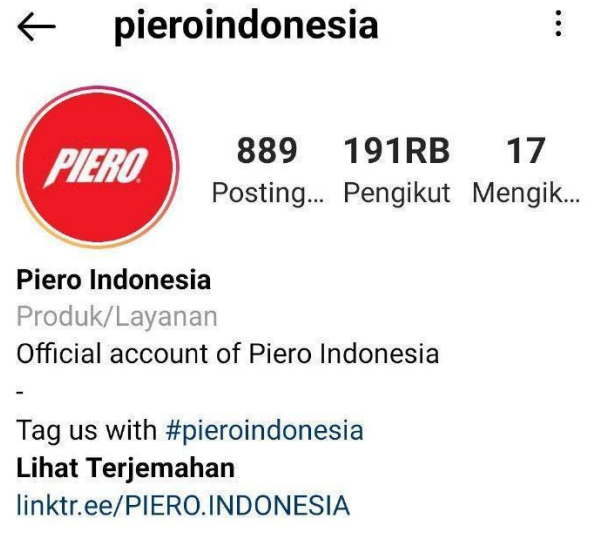

\begin{tabular}{|l|l|l|}
\hline \multicolumn{3}{|c|}{ @ihat Toko } \\
\hline Ikuti & Kirim P... & Email \\
\hline
\end{tabular}

Gambar 3. Akun Instagram Piero Indonesia

Sumber : https://instagram.com/pieroindonesia (akses pada 25-10-2021)

\section{Sepatu Compass}

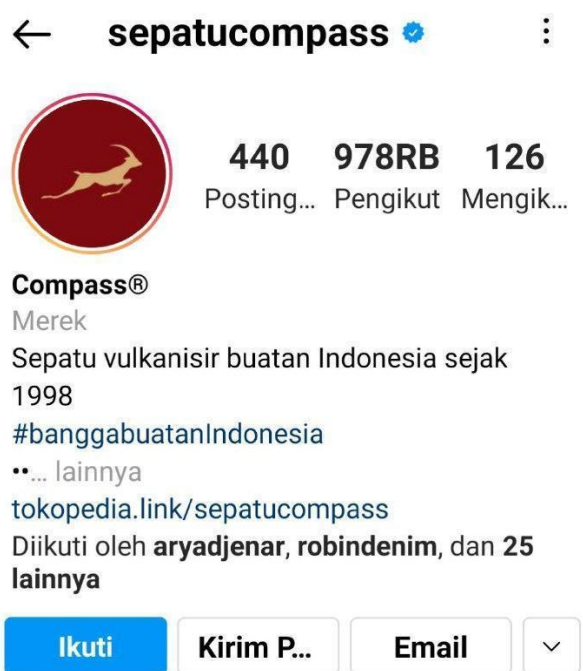

Gambar 4. Akun Instagram Sepatu Compass

Sumber : https://instagram.com/sepatucompass (akses pada 25-10-2021) 


\section{Sagara Bootmaker Indonesia}

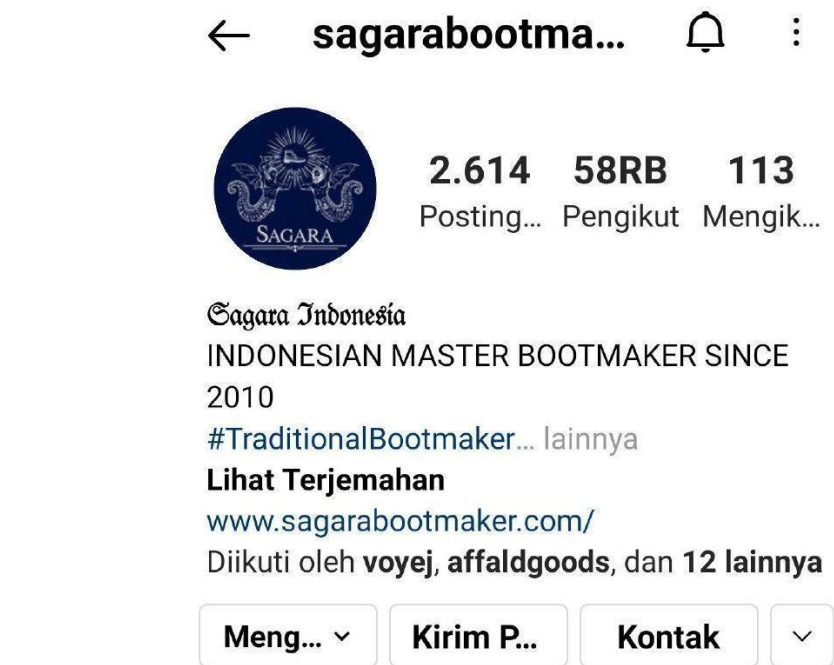

Gambar 5. Akun Instagram Sagara Indonesia

Sumber : https://instagram.com/sagarabootmaker (akses pada 25-10-2021)

Dari kelima akun Instagram 5 Sepatu Lokal Terbaik Versi Dr. Tirta, peneliti menemukan nilai dari masing-masing variabel yang ada untuk menghitung rasio Video Comments to Video Views dari setiap akun. Pada akun Instagram terdapat 8 variabel, diantaranya yaitu :

1. Postingan

2. Followers

3. Following

4. Video Likes

5. Video Comments

6. Video Views

7. Picture Likes

8. Picture Comments

Dari kedelapan variabel tersebut peneliti hanya fokus untuk menemukan hasil dari 2 variabel, yaitu :

1. Video Comments

2. Video Views

Dari kedua variabel tersebut kemudian dianalisis sehingga menemukan nilai rata-rata dari variabel video comments dan variabel video views. Untuk menghitung nilai rata-rata dari variabel video comments dan variabel video views yaitu dengan cara mengambil minimal 10 postingan kemudian dihitung sehingga menemukan nilai rata-rata dari masing-masing variabel. Berikut merupakan tabel nilai rata-rata dari masing-masing Sepatu Lokal Terbaik versi Dr. Tirta, yaitu : 
Tabel 1. Analisa Nilai Rata-Rata Nilai Variabel Video Comments dan Video Views Akun Instagram Ventela Shoes

\begin{tabular}{|c|r|r|}
\hline No & $\begin{array}{c}\text { Video } \\
\text { Comment }\end{array}$ & $\begin{array}{l}\text { Video } \\
\text { Views }\end{array}$ \\
\hline 1 & 308 & 101.760 \\
\hline 2 & 137 & 137.812 \\
\hline 3 & 165 & 227.300 \\
\hline 4 & 98 & 117.448 \\
\hline 5 & 72 & 49.433 \\
\hline 6 & 124 & 72.731 \\
\hline 7 & 201 & 112.874 \\
\hline 8 & 527 & 149.565 \\
\hline 9 & 248 & 134.214 \\
\hline 10 & 184 & 115.709 \\
\hline Total & $\mathbf{2 0 6}$ & $\mathbf{1 2 1 . 8 8 5}$ \\
\hline
\end{tabular}

Sumber : Pengolah Data Excel

Tabel 2. Analisa Nilai Rata-Rata Nilai Variabel Video Comments dan Video Views Akun Instagram League Indonesia

\begin{tabular}{|c|r|r|}
\hline No & \multicolumn{1}{|c|}{$\begin{array}{c}\text { Video } \\
\text { Comment }\end{array}$} & \multicolumn{1}{c|}{$\begin{array}{c}\text { Video } \\
\text { Views }\end{array}$} \\
\hline 1 & 0 & 334 \\
\hline 2 & 0 & 1.627 \\
\hline 3 & 9 & 2.310 \\
\hline 4 & 2 & 7.140 \\
\hline 5 & 0 & 1.645 \\
\hline 6 & 0 & 376 \\
\hline 7 & 1 & 2.814 \\
\hline 8 & 0 & 1.008 \\
\hline 9 & 0 & 1.262 \\
\hline 10 & 1 & 655 \\
\hline Total & $\mathbf{1}$ & $\mathbf{1 . 9 1 7}$ \\
\hline
\end{tabular}

Sumber : Pengolah Data Excel 
Tabel 3. Analisa Nilai Rata-Rata Nilai Variabel Video Comments dan Video Views Akun Instagram Piero Indonesia

\begin{tabular}{|c|r|r|}
\hline No & $\begin{array}{c}|c| \\
\text { Video } \\
\text { Comment }\end{array}$ & $\begin{array}{c}\text { Video } \\
\text { Views }\end{array}$ \\
\hline 1 & 11 & 5.024 \\
\hline 2 & 41 & 20.532 \\
\hline 3 & 0 & 4.391 \\
\hline 4 & 4 & 6.214 \\
\hline 5 & 83 & 33.559 \\
\hline 6 & 26 & 18.931 \\
\hline 7 & 4 & 10.244 \\
\hline 8 & 20 & 13.291 \\
\hline 9 & 6 & 19.023 \\
\hline 10 & 8 & 9.762 \\
\hline Total & $\mathbf{2 0}$ & $\mathbf{1 4 . 0 9 7}$ \\
\hline
\end{tabular}

Tabel 4. Analisa Nilai Rata-Rata Nilai Variabel Video Comments dan Video Views Akun Instagram Sepatu Compass

\begin{tabular}{|c|r|r|}
\hline No & $\begin{array}{c}|c| \\
\text { Video } \\
\text { Comment }\end{array}$ & $\begin{array}{c}\text { Video } \\
\text { Views }\end{array}$ \\
\hline 1 & 196 & 58.172 \\
\hline 2 & 205 & 57.609 \\
\hline 3 & 333 & 91.071 \\
\hline 4 & 159 & 69.596 \\
\hline 5 & 151 & 48.838 \\
\hline 6 & 172 & 96.767 \\
\hline 7 & 313 & 121.723 \\
\hline 8 & 191 & 60.536 \\
\hline 9 & 191 & 98.016 \\
\hline 10 & 692 & 172.049 \\
\hline Total & $\mathbf{2 6 0}$ & $\mathbf{8 7 . 4 3 8}$ \\
\hline
\end{tabular}

Sumber : Pengolah Data Excel 
Tabel 5. Analisa Rata-Rata Nilai Variabel Video Comments dan Video Views Akun Instagram Sagara Indonesia

\begin{tabular}{|c|r|r|}
\hline No & $\begin{array}{c}\text { Video } \\
\text { Comment }\end{array}$ & $\begin{array}{c}\text { Video } \\
\text { Views }\end{array}$ \\
\hline 1 & 7 & 3.407 \\
\hline 2 & 8 & 5.119 \\
\hline 3 & 2 & 2.687 \\
\hline 4 & 13 & 4.689 \\
\hline 5 & 13 & 2.375 \\
\hline 6 & 1 & 3.511 \\
\hline 7 & 0 & 1.425 \\
\hline 8 & 8 & 4.912 \\
\hline 9 & 5 & 1.404 \\
\hline 10 & 3 & 4.657 \\
\hline Total & $\mathbf{6}$ & $\mathbf{3 . 4 1 9}$ \\
\hline \multicolumn{2}{|r|}{ Sumber $:$ Pengolah Data Excel } \\
\hline
\end{tabular}

Setelah menghitung nilai rata-rata tersebut, maka akan menemukan hasil akhir nilai rata-rata dari variabel video comments dan

Tabel 6. Nilai Variabel Pada Akun Instagram 5 Sepatu Lokal Terbaik Versi Dr. Tirta

\begin{tabular}{|c|c|c|c|c|c|}
\hline Variable & $\begin{array}{c}\text { VENTELA } \\
\text { SHOES }\end{array}$ & LEAGUE & PIERO & COMPASS & $\begin{array}{c}\text { SAGARA } \\
\text { BOOTS }\end{array}$ \\
\hline $\begin{array}{c}\text { Video } \\
\text { Comments }\end{array}$ & 206 & 1 & 20 & 260 & 6 \\
\hline Video Views & 121885 & 1917 & 14097 & 87438 & 3419 \\
\hline \multicolumn{7}{|c}{ Sumber : Pengolah Data Excel }
\end{tabular}

Pada akun Instagram terdapat 14 rasio yang relevan digunakan untuk mengukur kredibilitas pada masing-masing akun. Namun pada penelitian kali ini hanya berfokus untuk menghitung Video Comments to Video Views Ratio. Untuk menghitung kredibilitas dari masing-masing akun Instagram setiap Brand Sepatu Lokal, peneliti menghitung dengan cara : variabel 1 akan dibagi dengan variabel 2 , sehingga ditemukan hasil analisis dari rasio tersebut.

Tabel 7. Hasil Perhitungan Rasio Akun Instagram

\begin{tabular}{|c|c|c|c|c|c|c|}
\hline NO & RATIO & $\begin{array}{c}\text { VENTELA } \\
\text { SHOES }\end{array}$ & LEAGUE & PIERO & COMPASS & $\begin{array}{c}\text { SAGARA } \\
\text { BOOTS }\end{array}$ \\
\hline 1 & $\begin{array}{c}\text { Video } \\
\text { Comments to } \\
\text { Video Views } \\
\text { Ratio }\end{array}$ & 0,00169341 & 0,00067811 & 0,00144001 & 0,00297698 & 0,00175510 \\
\hline
\end{tabular}


Video Comments to Video Views Ratio memiliki karakteristik yang tinggi, artinya semakin tinggi nilai yang dihasilkan maka semakin baik kredibilitas dari performa akun tersebut. Untuk memberikan peringkat pada masing-masing Brand Sepatu Lokal, peneliti memberikan angka 5 kepada brand yang mendapatkan nilai tertinggi dan angka 1 untuk brand sepatu lokal yang mendapatkan nilai terendah. Berikut merupakan tabel urutan nilai yang dihasilkan oleh masing-masing brand sepatu lokal.

Tabel 8. Nilai Rasio Akun Instagram 5 Sepatu Lokal Terbaik Versi Dr. Tirta

\begin{tabular}{|c|c|c|c|c|c|}
\hline \multirow{2}{*}{ RATIO } & \multicolumn{5}{|c|}{ NILAI } \\
\cline { 2 - 6 } & $\begin{array}{c}\text { VENTELA } \\
\text { SHOES }\end{array}$ & LEAGUE & PIERO & COMPASS & $\begin{array}{c}\text { SAGARA } \\
\text { BOOTS }\end{array}$ \\
\hline $\begin{array}{c}\text { Video } \\
\text { Comments to } \\
\text { Video Views } \\
\text { Ratio }\end{array}$ & 3 & 1 & 2 & 5 & 4 \\
\hline
\end{tabular}

Dari Tabel Nilai Rasio Akun 5 Sepatu Lokal Terbaik Versi Dr. Tirta dapat simpulkan bahwa Sepatu Compass mendapatkan nilai tertinggi untuk rasio Video Comments to Video Views. Sedangkan akun Instagram League Indonesia mendapatkan nilai terendah untuk rasio ini. Jadi, pada penelitian ini Sepatu Compass memiliki kredibilitas performa yang lebih baik dibandingkan dengan brand sepatu lokal yang lainnya. 


\section{DAFTAR PUSTAKA}

Adi Nugroho, D., \& Setyo Iriani, S. (n.d.). PENGARUH PROMOSI PENJUALAN DAN CELEBRITY ENDORSER TERHADAP NIAT BELI FASHION BRAND LOKAL GIYOMI PADA GENERASI Y DAN Z. In Jurnal Ilmu Manajemen (Vol. 8).

Dwi, E., \& Watie, S. (2011). Komunikasi dan Media Sosial (Communications and Social Media): Vol. III (Issue 1). http://id.wikipedia.org/wiki/Media_sos

Eswanto, O. :, Rahayu, S., Siti Laela, ); Tinggi, S., Ekonomi, I., \& Jakarta, I. (n.d.). PENGARUH MINAT BERWIRAUSAHA DAN PENGGUNAAN SOSIAL MEDIA TERHADAP KEWIRAUSAHAAN MAHASISWA (Vol. 20). http://ejurnal.stieipwija.ac.id/index.php/jpw

Gan Giantika, G. (2018). Pemanfaatan Blog Pribadi Di Instagram Sebagai Media Komunikasi Parenting (Studi Deskriptif Kualitatif Akun Instagram @annisast).12-12. http://ejournal.bsi.ac.id/ejurnal/index.php/jkom

Maryam, Siti, Isrok'atun Isrok'atun, and Ani Nur Aeni. 2016. "PENDEKATAN EKSPLORATIF UNTUK MENINGKATKAN KEMAMPUAN REPRESENTASI MATEMATIS DAN KEPERCAYAAN DIRI SISWA.”Jurnal Pena Ilmiah 1 (1): 551-60. https://doi.org/10.23819/PI.V1I1.2984.

Putu, I., \& Permana, H. (2021). Analisis Rasio Pada Instagram Untuk Penelitian Kualitatif Menggunakan Metode Ekploratif. Jurnal Sistem Informasi Dan Komputer Terapan Indonesia (JSIKTI), 3(3), 44-56. https://doi.org/10.22146/jsikti

Rankuti, Freddy. 2015. “Buku Riset Pemasaran.” 2015.

Soraya Program Studi Periklanan, I., BSI Jakarta Akademi Komunikasi Bina Sarana Informatika Jakarta Jl Kayu Jati, A., \& Timur, J. (2017). Personal Branding Laudya Cynthia Bella Melalui Instagram (Studi Deskriptif Kualitatif Pada Akun Instagram @ Bandungmakuta). In Jurnal Komunikasi (Vol. 2). www.antara.com

Wayan Ekawati, N. (2015). PENGARUH CELEBRITY ENDORSER, BRAND IMAGE DAN PERSEPSI KUALITAS TERHADAP NIAT BELI SEPEDA MOTOR HONDA SCOOPY DI KOTA DENPASAR I Putu Gede Handre Haryantana'. 4(9), 2806-2830.

“5 Sepatu Lokal Terbaik Versi Dr. Tirta - Kompas.com.” n.d. Accessed Oktober 15, 2021. https:/lifestyle.kompas.com/read/2020/03/09/150809220/5-sepatu-lokal-terbaik-versi-d rtirta. 